\title{
Potential ecological and human health risks of heavy metals in surface soils associated with iron ore mining in Pahang, Malaysia
}

\begin{abstract}
The composition of heavy metals (and metalloid) in surface soils of iron ore mine-impacted areas has been evaluated of their potential ecological and human health risks. The mining areas included seven selected locations in the vicinity of active and abandoned iron oremining sites in Pahang, Malaysia. Heavy metals such as $\mathrm{Fe}, \mathrm{Mn}, \mathrm{Cu}, \mathrm{Zn}, \mathrm{Co}, \mathrm{Pb}, \mathrm{Cr}, \mathrm{Ni}$, and $\mathrm{Cd}$ and metalloid As were present in the mining soils of the studied area, while $\mathrm{Cu}$ was found exceeding the soil guideline value at all sampling locations. However, the assessment of the potential ecological risk index (RI) indicated low ecological risk (RI between 44 and 128) with respect to $\mathrm{Cd}, \mathrm{Pb}, \mathrm{Cu}, \mathrm{As}, \mathrm{Zn}, \mathrm{Co}$, and $\mathrm{Ni}$ in the surface soils. Contributions of potential ecological risk (Eri)by metal elements to the total potential ecological RI were evident for $\mathrm{Cd}, \mathrm{As}, \mathrm{Pb}$, and $\mathrm{Cu}$. Contribution of $\mathrm{Cu}$ appears to be consistently greater in the abandoned mining area compared to active iron ore-mining site. For non-carcinogenic risk, no significant potential health risk was found to both children and adults as the hazard indices (HIs) were all below than 1. The lifetime cancer risk (LCR) indicated that As has greater potential carcinogenic risk compared to other metals that may induce carcinogenic effects such as $\mathrm{Pb}$, $\mathrm{Cr}$, and $\mathrm{Cd}$, while the LCR of As for children fell within tolerable range for regulatory purposes. Irrespective of carcinogenic or non-carcinogenic risk, greater potential health risk was found among children (by an order of magnitude higher for most metals) compared to adults. The hazard quotient (HQ) and cancer risk indicated that the pathways for the risk to occur were found to be in the order of ingestion > dermal > inhalation. Overall, findings showed that some metals and metalloid were still present at comparable concentrations even long after cessation of the iron ore-mining activities.
\end{abstract}

Keyword: Ecological risk index; Health risk index; Heavy metal; Iron ore; Mining 